\title{
IMPACTO DO CURRÍCULO PORTUGUÊS DAS CIÊNCIAS FÍSICAS E NATURAIS NAS PRÁTICAS DOCENTES
}

\section{The impact of the Natural and Physical Sciences Portuguese Curriculum on teachers' practices}

\author{
Idalina Martins ${ }^{1}$ \\ Marta Abelha ${ }^{2}$ \\ Nilza Costa ${ }^{3}$ \\ Maria do Céu Roldão ${ }^{4}$
}

\begin{abstract}
Resumo: Este artigo pretende disseminar resultados de uma investigação cuja principal finalidade era compreender o impacto do processo de Reorganização Curricular do Ensino Básico português nas práticas curriculares e dinâmicas de trabalho de professores de Ciências Físicas e Naturais. O primeiro momento do estudo empírico assumiu uma natureza quantitativa, referindo-se os resultados a 1122 questionários preenchidos por professores que lecionavam as disciplinas da área das Ciências Físicas e Naturais. O segundo momento, de índole qualitativa, pretendeu aprofundar os dados quantitativos, através da realização de entrevistas a seis dos professores participantes no primeiro momento. Os resultados obtidos sugerem uma apropriação epidérmica dos conceitos centrais ao atual discurso educativo e indiciam que a implementação do processo de Reorganização Curricular não se traduziu em mudanças efetivas de práticas e dinâmicas de trabalho docente. Face a esta realidade, consideramos imprescindível uma ação concertada entre professores, instituições de formação inicial e contínua e a administração central.

Palavras-chave: Currículo. Ciências Físicas e Naturais. Competência docente. Ensino básico. Portugal.
\end{abstract}

\begin{abstract}
This paper intends to disseminate the results of a study whose main aim was to understand the impact of the Basic Education Curricular Reorganisation for the curricular practices and collaboration dynamics of Natural and Physical Sciences teachers. The empirical study adopted a quantitative approach and the results report on 1122 questionnaires completed by Natural and Physical Sciences teachers. To deepen these results, we collected qualitative data, obtained from interviews with six Natural and Physical Sciences teachers who participated in the first part of the study. The results obtained suggest a superficial appropriation of the central concepts concerning current education discourse and indicate that the implementation of the Basic Education Curriculum in Portugal doesn't produce effective changes in teachers' practices. We consider this requires essential and concerted action between teachers, Education Institutes and Central Administration.
\end{abstract}

Keywords: Curriculum. Natural and Physical Sciences. Competency. Teachers`collaboration.

\footnotetext{
${ }^{1}$ Doutoranda em Didática e Formação, Departamento de Educação, Centro de Investigação Didática e Tecnologia na Formação de Formadores (CIDTFF), Universidade de Aveiro (UA). Aveiro, Portugal. <idalinamartins@ua.pt> ${ }^{2}$ Doutora em Didática e Formação, CIDTFF, UA. Aveiro, Portugal. <mabelha@ua.pt>

${ }^{3}$ Docente, Departamento de Educação, CIDTFF, UA. Aveiro, Portugal. <nilzacosta@ua.pt>

${ }^{4}$ Docente, Departamento de Ciências de Educação da Criança, Centro de Estudos da Criança (CESC), Universidade do Minho (UM). Braga, Portugal.<maria.roldao@netvisao.pt>

${ }^{1}$ Universidade de Aveiro, Departamento de Educação, LAQE

Campus Universitário de Santiago

Aveiro, Portugal

3810-193

771

Ciência \&̊ Educação, v. 17, n. 4, p. 771-788, 2011
} 
Martins, I. et al.

\section{Introdução}

Nas últimas duas décadas, o interesse dos alunos por temáticas científicas tem vindo a decrescer, realidade confirmada por estudos internacionais e relatórios sobre ensino e educação em ciência, designadamente Organisation for Economic Co-Operation and Development (2007), European Commission (2007), Osborne e Dillon (2008). Segundo estes estudos e relatórios é urgente redesenhar os currículos de ciências com o intuito de assegurar uma educação científica contextualizada e adequada às necessidades e interesses da generalidade dos alunos.

Outro dos problemas diagnosticados relaciona-se com as abordagens pedagógicodidáticas privilegiadas no ensino das ciências, as quais, segundo estes estudos e relatórios, não estão a conseguir motivar e aproximar os alunos de temas científicos. McWilliam, Poronnik e Taylor (2008) defendem que os jovens preferem abordagens ativas do conhecimento, desmotivando-se, frequentemente, com abordagens passivas e focalizadas na transmissão de conhecimentos. Neste sentido, o relatório de Osborne e Dillon (2008) invoca a necessidade dos currículos e das abordagens pedagógico-didáticas valorizarem e contemplarem o trabalho experimental e as atividades de pesquisa e, por outro lado, alerta para questões relacionadas com a qualidade da formação inicial e contínua dos professores de ciências.

Estes problemas têm-se refletido no currículo das ciências de vários países, inclusive de Portugal, onde, com a implementação do processo de Reorganização Curricular do Ensino Básico $^{5}$, foi proposta uma nova perspectiva curricular, designadamente para o ensino das Ciências Físicas e Naturais (CFN). Focalizando-nos no caso particular das CFN, a construção desta nova perspectiva curricular resultou de um trabalho de equipa que envolveu investigadores das áreas específicas (Biologia, Física e Química), especialistas no campo da educação e do currículo e representantes de organizações científicas e associações de professores. O trabalho desta equipe culminou no atual currículo nacional de CFN (PORTUGAL, 2001a) e na elaboração de um documento de apoio (PORTUGAL, 2001b) dirigido aos professores do $3^{\circ} \mathrm{Ciclo}$ que lecionam as disciplinas de Ciências Naturais (CN) e Ciências Físico-Químicas (CFQ).

A publicação destes documentos foi complementada com alterações a nível legislativo, passando a consagrar-se maior ênfase ao ensino experimental das ciências. Com efeito, defiram-se algumas linhas orientadoras para o ensino das ciências, das quais salientamos:

i) A participação dos alunos em projetos de natureza interdisciplinar,

ii) A concretização de experiências educativas diferenciadas e perspectivadas segundo uma abordagem Ciência, Tecnologia e Sociedade (CTS),

iii) $\mathrm{O}$ desenvolvimento nos alunos de competências de literacia científica, nomeadamente nos domínios do conhecimento, raciocínio, comunicação e atitudes.

A definição destas linhas orientadoras e respectiva (re)apropriação no contexto das práticas curriculares pressupõe a assunção de alguns desafios por parte dos professores de ciências, em particular tomadas de decisão eficazes ao nível da gestão, adequação, planificação

${ }^{5}$ Em Portugal, o Ensino Básico é de caráter obrigatório e tem a duração de nove anos, subdivididos em três ciclos de aprendizagem, a saber: $1 .^{\circ}$ ciclo - quatro anos de escolaridade; $2 .^{\circ}$ ciclo - dois anos de escolaridade; 3. ${ }^{\circ}$ ciclo - três anos de escolaridade. 
de atividades e organização concertada das disciplinas desta área curricular (GALVÃO; FREIRE, 2004).

Todavia, apesar de no plano discursivo ser comumente aceito, por professores e investigadores, que as práticas de colaboração docente são um fator indispensável ao desenvolvimento profissional docente (HORN, 2005; SAWYER; RIMM-KAUFMAN, 2007), refletindo-se na eficácia do trabalho docente e na qualidade dos processos de ensino e aprendizagem, verifica-se que nas escolas tende a prevalecer uma cultura de individualismo (HARGREAVES, 1998). Esta realidade carece de maior compreensão dado que, segundo diversos autores, a saber Flinders (1988), Fullan e Hargreaves, (2001) e Little (1990), é demasiado simplista atribuir a responsabilidade da sua prevalência unicamente aos professores.

A implementação do processo de Reorganização Curricular do Ensino Básico tornou emergente a necessidade de se desenvolverem práticas de colaboração docente para promover experiências educativas mais globalizantes, contextualizadas e significativas para os alunos. No caso das CFN a emergência de práticas de colaboração docente ainda é mais enfatizada, solicitando-se aos professores de ciências:

i) O desenvolvimento de trabalho colaborativo docente entre os professores que asseguram a lecionação das disciplinas de $\mathrm{CN}$ e de $\mathrm{CFQ}$, recorrendo ao regime de co-docência (par pedagógico), sempre que as temáticas o proporcionarem, uma vez que fomenta a articulação de saberes e permite a construção de uma visão holística da ciência (GALVÃO; FREIRE, 2004; LEE; ERDOGAN, 2007);

ii) Uma articulação curricular concertada dos conteúdos das disciplinas de $\mathrm{CN}$ e $\mathrm{CFQ}$, para esbater a concepção curricular cumulativa e enciclopédica de matriz disciplinar, onde as ciências surgem como isoladas, compartimentadas e independentes umas das outras (CACHAPUZ; PRAIA; JORGE, 2002).

Nesta perspectiva, e conscientes de que a realização de mudanças curriculares é um processo complexo e moroso, não se realiza por decreto, apresentamos neste artigo os resultados de uma investigação em rede cuja problemática se situa na compreensão do impacto do processo de Reorganização Curricular do Ensino Básico segundo duas perspectivas, nomeadamente a do desenvolvimento de práticas curriculares e de dinâmicas de trabalho docente.

\section{Problema e metodologia}

Como já referimos, a problemática desta investigação enquadra-se no contexto das mudanças curriculares e respectivas implicações nas práticas curriculares e nas dinâmicas de trabalho docente. Neste caso particular, o enfoque situa-se ao nível da compreensão do impacto do processo de Reorganização Curricular do Ensino Básico, junto de professores que asseguravam a lecionação das disciplinas da área curricular de CFN.

O estudo empírico que sustentou esta investigação decorreu em dois momentos distintos. No primeiro, de natureza predominantemente quantitativa, privilegiou-se como técnica de recolha de dados o inquérito por questionário. Este instrumento, previamente validado interna e externamente, foi aplicado a 2718 professores que, no ano letivo de 2006/2007, lecionavam as disciplinas da área curricular de CFN nas 297 escolas públicas do ensino básico português $\left(2^{\circ}\right.$ e $3^{\circ}$ ciclos), afetas à região norte do país. 
Martins, I. et al.

O questionário encontrava-se estruturado em quatro secções, respectivamente: i) Caracterização pessoal e profissional, ii) Representação conceptual, iii) Práticas e dinâmicas de trabalho docente e iv) Colaboração na segunda fase da investigação. Nas diferentes secções privilegiaram-se perguntas fechadas e de escolha múltipla, na forma de perguntas em leque e de avaliação ou de estimação.

A aplicação deste inquérito por questionário visava, sobretudo: i) averiguar o nível de apropriação de conceitos que assumiram maior centralidade no discurso educativo, especificamente "Currículo", "Gestão curricular", "Desenvolvimento curricular", "Projeto", "Trabalho colaborativo" e "Competência", ii) compreender possíveis alterações de práticas e dinâmicas de trabalho docente resultantes da implementação do processo de Reorganização Curricular e iii) reunir um conjunto de professores de CFN disponíveis a colaborar no segundo momento do estudo. Os dados obtidos foram analisados estatisticamente utilizando um software informático de gestão e análise de dados, o "Statistical Package for the Social Sciences" (SPSS versão 15.0).

O segundo momento do estudo empírico decorreu no início do ano letivo de 2007/ 2008 e consistiu na realização de entrevistas semiestruturadas a seis professores de CFN. Uma vez que era nosso objetivo focalizarmo-nos na compreensão das práticas e dinâmicas de trabalho desenvolvidas por professores de CFN a lecionarem no $3 .^{\circ}$ ciclo do ensino básico, o conjunto inicial de professores disponíveis reduziu significativamente $(n=33)$; pelo que os seis entrevistados foram os que responderam em tempo útil, reiterando a sua disponibilidade para realizar a entrevista.

As entrevistas visavam aprofundar os dados obtidos através da aplicação do questionário e encontravam-se organizadas em três secções: designadamente: i) Representação conceptual e gestão do currículo, ii) Abordagem curricular por competências e iii) Dinâmicas de trabalho docente. Face à natureza qualitativa destes dados, a técnica de tratamento utilizada foi a análise de conteúdo, recorrendo ao software informático "Non-numerical Unstructured Data Indexing Searching and Theorizing" (NUD*IST).

\section{Resultados e discussão}

Os resultados apresentados são de índole quantitativa e qualitativa, reportando-se os primeiros à recepção de 1122 questionários, corretamente preenchidos e remetidos por 158 escolas, valores que traduzem taxas de devolução de $41,3 \%$ e $53,2 \%$, respectivamente. Por sua vez, os dados de natureza qualitativa referem-se à análise de conteúdo de seis entrevistas de aprofundamento dos dados obtidos com a administração do inquérito por questionário.

Apesar do nível satisfatório das taxas de devolução anteriormente referidas, somente $15,2 \%$ dos professores respondentes se disponibilizou a colaborar no segundo momento do estudo empírico, o qual consistia na resposta a uma entrevista, partilha de materiais didáticos e possível participação num percurso formativo. Importa destacar que a receptividade foi mais significativa nos professores respondentes com algum tipo de formação pós-graduada, indiciando que estes poderão estar mais sensibilizados para a participação em investigações na área das Ciências da Educação. Esta maior receptividade poderá dever-se a várias razões, por um lado, ao facto de já terem experienciado as resistências que os docentes revelam quando soli- 
citados a colaborar em investigações no campo da educação. Por outro lado, talvez estejam mais conscientes da necessidade de acompanhar a investigação educacional ou mais exigentes e ávidos por se apropriarem de conhecimentos relativos ao seu contexto profissional.

Os resultados que de seguida se apresentam estão organizados em quatro secções, intercalando-se e relacionando-se dados quantitativos e qualitativos.

\section{a) Caracterização pessoal e profissional dos professores envolvidos no estudo}

A análise dos dados obtidos com a administração dos questionários permitiu-nos verificar que a média de idades dos professores respondentes era de 38,4 anos e que o género feminino era o predominante $(80,9 \%)$, confirmando resultados de estudos, nomeadamente Lang (2008); Nóvoa (1995), Tardif e Lessard (2005), sobre questões de género na profissão docente.

Importa salientar que a generalidade dos respondentes $(84,8 \%)$ possuía como grau académico a licenciatura e que mais de metade $(57,4 \%)$ eram professores efetivos a exercer funções numa escola, lecionando há, pelo menos, sete anos, facto que denota alguma estabilidade profissional.

Nos seis professores entrevistados o género predominante era, igualmente, o feminino (quatro elementos), a média de idades subia ligeiramente para 39,0 anos, todos se encontravam afetos a um quadro de escola e lecionavam há mais de sete anos, denunciando uma situação de estabilidade profissional semelhante à dos professores respondentes ao questionário. Dois dos entrevistados haviam complementado a sua formação académica inicial com a obtenção do grau de mestre em áreas relacionadas com a educação.

\section{b) Representação conceptual e gestão do currículo}

A implementação do processo de Reorganização Curricular do Ensino Básico levou a que alguns conceitos assumissem maior centralidade, quer no discurso educativo como nos documentos curriculares, destacando-se os de "Currículo", "Gestão curricular", "Desenvolvimento curricular", "Projeto", "Trabalho colaborativo" e "Competência". Assim, para compreendermos o nível de apropriação destes conceitos junto dos professores de CFN, e na tentativa de evitarmos respostas orientadas pela discursividade dominante, solicitámos que assinalassem as duas representações conceptuais que, segundo os inquiridos, melhor refletissem o entendimento que os seus pares atribuíam a cada um dos conceitos anteriormente referidos.

Importa mencionar que para cada um dos conceitos se apresentou um conjunto de expressões das quais apenas duas se encontravam formuladas em consonância com referenciais teóricos atuais. Deste modo, na Tabela 1 sistematizam-se, por conceito, os resultados relativos ao valor percentual de respostas obtidas em conformidade com os referenciais teóricos de base.

Tendo por referência o entendimento teoricamente fundamentado, estes resultados indiciam que os conceitos de "Competência" e "Projeto" são os que aparentam estar mais apropriados pelos professores. Este facto, em nosso entender, resulta da prevalência que estes conceitos assumem nos documentos oficiais, estando associados a normativos a cumprir na prática diária das escolas. Em contrapartida, os conceitos de "Gestão curricular" e "Desenvolvimento curricular" são os que, aparentemente, estão menos apropriados pelos professores.

A reduzida apropriação do conceito de "Gestão curricular" é consentânea com o discurso dos professores entrevistados, dado que apenas um manifestou um entendimento 
Martins, I. et al.

Tabela 1. Representação conceptual de conceitos emergentes no atual discurso educativo.

\begin{tabular}{|c|c|c|}
\hline Conceito & Teoricamente fundamentado & Percentagem \\
\hline Competência & $\begin{array}{l}\text {. Organização de conhecimentos adquiridos, apropriados por um } \\
\text { sujeito, e colocados em ação perante situações problemáticas. } \\
\text {. Apropriação, uso e mobilização dos saberes curriculares face a } \\
\text { uma situação. }\end{array}$ & $61,4 \%$ \\
\hline Desenvolvimento curricular & $\begin{array}{l}\text {. Processo de tomadas de decisão sobre o currículo por parte de } \\
\text { todos os intervenientes educativos. } \\
\text {. Modo como em cada escola e turma se planificam, desenvolvem e } \\
\text { avaliam as diferentes situações de ensino e aprendizagem, tendo } \\
\text { por referência as metas e opções de gestão curricular assumidas. }\end{array}$ & $28,3 \%$ \\
\hline Gestão curricular & $\begin{array}{l}\text { Decisão, a nível de Conselho de Turma e em articulação com os } \\
\text { Departamentos Curriculares, sobre o que ensinar e porquê, como, } \\
\text { quando, com que prioridades, com que meios, com que } \\
\text { organização, com que resultados. } \\
\text {. Reconstrução contextualizada do currículo proposto a nível } \\
\text { nacional. }\end{array}$ & $18,9 \%$ \\
\hline Projeto & $\begin{array}{l}\text {. Conjunto de atividades de ensino e aprendizagem dirigidas a } \\
\text { finalidades determinadas, que correspondam a necessidades } \\
\text { sentidas pelos agentes envolvidos. } \\
\text {. Modo de concretizar as orientações curriculares de âmbito } \\
\text { nacional face a um contexto específico, implicando uma constante } \\
\text { avaliação de resultados e possíveis reformulações. }\end{array}$ & $43,0 \%$ \\
\hline Trabalho colaborativo & $\begin{array}{l}\text { - Tomada conjunta de decisões sobre aspectos inerentes à prática } \\
\text { letiva, tais como, planificações, construção de materiais didáticos, } \\
\text { critérios de avaliação e partilha de experiências pedagógicas. } \\
\text {. Processo de interação em que os professores, com base numa } \\
\text { relação de interdependência e de responsabilidade, decidem sobre } \\
\text { as opções curriculares e práticas docentes a adotar. }\end{array}$ & $36,8 \%$ \\
\hline
\end{tabular}

Fonte: Os autores.

próximo do teoricamente fundamentado, ao declarar que: "Gerir o currículo é adaptar o currículo nacional ao contexto real da escola, mais concretamente ao contexto de cada turma. São as estratégias de aprendizagem que se pretendem desenvolver com aqueles alunos" (Professor 5).

Por conseguinte, a frequência de realização de práticas de gestão curricular foi considerada escassa pela generalidade dos entrevistados, quer no contexto do departamento curricular como no do conselho de turma. Os principais constrangimentos apontados à realização destas práticas foram o excesso de burocracia, atualmente, subjacente ao exercício do trabalho docente e a falta de tempo e de motivação pessoal. O discurso do Professor 1 evidencia este último constrangimento de natureza intrínseca: "A gestão do currículo, na minha escola, resume-se ao papel. Se os professores têm vontade faz-se".

Segundo estes professores, a existência de maiores índices de colaboração docente e de horários de trabalho que contemplassem tempos comuns para reuniões eram considerados exemplos de fatores passíveis de potenciar o desenvolvimento de práticas de gestão curricular. Como exemplo, o Professor 4 declarou que: "Se cada professor tivesse tempo real de trabalho para além das suas aulas, então poder-se-ia proceder a um efetivo trabalho de gestão curricular". 
A frequência de realização de articulações curriculares, enquanto modo de operacionalizar a gestão curricular, foi, igualmente, reduzida, focalizando-se os exemplos em atividades desenvolvidas fora do contexto de sala de aula, especificamente em visitas de estudo. Geralmente, a planificação destas articulações ocorria de um modo informal: "A planificação é feita por contactos informais, fora das reuniões, em encontros do dia-a-dia (sala de professores, internet)" Professor 2.

Estes resultados indiciam que a colaboração entre pares, imprescindível à realização de articulações curriculares, era mais frequente em contextos informais, corroborando estudos realizados por Hargreaves (1998), Miskel, McDonald e Bloom (1983), Sawyer e RimmKaufman (2007). Por sua vez, os constrangimentos assinalados à realização de mais articulações curriculares foram semelhantes aos referidos, anteriormente, em relação às práticas de gestão curricular.

Contudo, e em consonância com estudos de Beane (2000) e Lopes (2008), os professores entrevistados reconheceram que o desenvolvimento de articulações curriculares tende a refletir-se em benefícios para os alunos, tanto ao nível da mobilização de conhecimentos como da construção de uma visão holística dos saberes. Neste contexto, o Professor 1 afirmou que: "Relacionar conteúdos, temas e conhecimentos permite aos alunos reconhecer uma sequencialidade e relação entre saberes, reconbecendo que o que aprendem numa área curricular tem aplicabilidade em outras" e o Professor 4 salientou que: "bá conteúdos comuns a diferentes disciplinas que justificam que se estabeleçam articulações para conferir aos alunos uma visão mais global e menos estanque dos saberes das diferentes disciplinas".

O Projeto Curricular de Turma (PCT), segundo Leite, Gomes e Fernandes (2001) e Roldão (2004a), é um instrumento de gestão curricular que pretende adequar o currículo nacional às especificidades dos alunos de cada turma, por conseguinte questionámos os entrevistados sobre a finalidade que atribuíam a este instrumento. A análise de conteúdo do discurso dos entrevistados permitiu-nos constatar que as opiniões eram divergentes, dado que quatro professores declararam que a principal finalidade do PCT se resumia ao cumprimento de legislação "O PCT é apenas o cumprimento de uma formalidade. É uma carga de trabalho inútil nos moldes em que está a funcionar" (Professor 1).

Em contrapartida, os outros dois entrevistados consideraram como finalidade do PCT a promoção do sucesso educativo dos alunos, sustentando que: "O PCT permite articular conhecimentos de várias áreas do saber, gerir o currículo, propiciar o sucesso e integrar os alunos na turma" (Professor 2) e que "O PCT serve para faz̧er a articulação e a junção de tudo o que vai acontecendo na turma, para conhecermos o ambiente da turma e a evolução das aprendizagens dos alunos. Também tem de evidenciar as dificuldades diagnosticadas e as estratégias adotadas para as colmatar" (Professor 6).

Apesar da concepção, aprovação e avaliação do PCT ser uma responsabilidade inerente ao conselho de turma, a generalidade dos entrevistados associou-a única e exclusivamente ao diretor de turma, alegando ser rara a participação dos restantes elementos do referido conselho.

Em suma, a escassa apropriação da generalidade dos conceitos, anteriormente mencionados, denuncia a prevalência de constrangimentos, quer no contexto do desenvolvimento de práticas curriculares e dinâmicas de trabalho docente, quer no contexto do desenvolvimento de competências nos alunos. Por sua vez, esta situação afigura-se, igualmente, como um constrangimento ao entendimento e finalidades atribuídas pelos entrevistados ao PCT. 
Martins, I. et al.

\section{c) Abordagem curricular por competências}

A implementação do processo de Reorganização Curricular do Ensino Básico e subsequente abordagem curricular por competências pressupõe mudanças no contexto das práticas curriculares desenvolvidas com os alunos. Deste modo, com a aplicação do questionário, também era nossa intenção averiguar se a implementação deste processo induziu os inquiridos a alterarem as suas práticas curriculares. Os resultados obtidos revelaram que somente 51,5\% dos professores respondentes afirmou ter introduzido alterações nas suas práticas curriculares.

No grupo dos seis professores entrevistados apenas um confirmou ter alterado as suas práticas, reportando-se a um acréscimo da intervenção dos alunos em contexto de sala de aula: "Alterei as estratégias de modo a aumentar o grau de intervenção dos alunos e dar-lhes mais autonomia" (Professor 1).

Os outros cinco professores entrevistados asseguraram não ter introduzido quaisquer alterações nas suas práticas curriculares, mantendo as mesmas estratégias de ensino. Como exemplo, ilustramos esta situação com o discurso do Professor 3: "Uso as mesmas estratégias que usava quando o currículo estava organizado por objetivos".

Focalizando-nos nos professores respondentes ao questionário que afirmaram ter alterado as suas práticas curriculares na sequência da implementação do processo de Reorganização Curricular, quisemos compreender as principais mudanças introduzidas. Assim, na Tabela 2 estão apresentadas, por ordem decrescente, situações curriculares cuja frequência de utilização aumentou significativamente:

Tabela 2. Situações curriculares cuja frequência de utilização aumentou.

\begin{tabular}{lc}
\hline \multicolumn{1}{c}{ Situações curriculares cuja frequência de utilização aumentou } & Percentagem \\
\hline Utilização de tecnologias de informação e comunicação em função das diferentes situações. & $74,8 \%$ \\
Debates sobre as problemáticas inerentes à Ciência, Tecnologia e Sociedade. & $64,8 \%$ \\
Integração de saberes transversais e multidisciplinares em contexto de sala de aula. & $60,6 \%$ \\
Concepção de estratégias que, relacionando Ciência, Tecnologia e Sociedade, promovam & $59,1 \%$ \\
um maior índice de autonomia nos alunos. & $55,4 \%$ \\
Modos de ensino e estratégias promotoras do desenvolvimento de competências nos e com & $53,5 \%$ \\
os alunos. & \\
Análise crítica de notícias veiculadas pelos meios de comunicação. &
\end{tabular}

Fonte: Os autores.

A utilização das Tecnologias de Informação e Comunicação (TIC), a promoção de situações de debate com os alunos sobre problemáticas CTS e a integração de saberes transversais foram as situações curriculares cujo acréscimo de utilização foi mais significativo. Este acréscimo poderá indiciar algum envolvimento dos professores respondentes com as linhas orientadoras do atual currículo das $\mathrm{CFN}$, as quais privilegiam o desenvolvimento nos alunos de competências de literacia científica. Com efeito, segundo alguns autores, em particular Laugksch (2000) e McWilliam, Poronnik e Taylor (2008), a formação de jovens cientificamente literatos é determinante para enfrentar os atuais desafios sociais e as incertezas associadas ao futuro profissional. 
O discurso dos professores entrevistados, relativamente a exemplos de situações promotoras do desenvolvimento de competências nos alunos, centralizou-se na realização de trabalho de grupo, de debates e de atividades experimentais. Estes exemplos evidenciam-se nas afirmações seguintes: "O trabalho de grupo sobre um tema definido, em que os alunos têm de elaborar uma sintese do tema e preparar uma apresentação aos colegas com recurso a suportes multimédia" (Professor 1); "Promovo mais o debate com os alunos, lanço questões para reflexão, reporto-me a situacõos do dia-a-dia para contextualizar os conteúdos que quero abordar e à exploração de notícias" (Professor 5) e "Privilegio as atividades experimentais, porque os alunos têm de observar, relacionar, tirar conclusões e de inferir acontecimentos" (Professor 6).

As afirmações anteriores estão em consonância com os resultados obtidos através da administração do inquérito por questionário, em particular ao nível do acréscimo de situações de debate com os alunos sobre problemáticas CTS. A contextualização das aprendizagens e a realização de atividades experimentais são outros exemplos de experiências educativas que, segundo o atual currículo das $\mathrm{CFN}$, promovem o desenvolvimento de competências específicas desta área curricular. Por outro lado, o recurso às TIC e às experiências educativas anteriormente referidas são abordagens curriculares que tendem a despertar o interesse dos alunos por temáticas científicas, aproximando-as da generalidade dos cidadãos e integrando-as nas conversas do dia-a-dia, como defendem DeBoer (2000) e Yalvac et al. (2007).

O discurso dos entrevistados permitiu constatar que as modalidades de avaliação privilegiadas eram a diagnóstica, a formativa e a sumativa. Os instrumentos de avaliação frequentemente utilizados por estes entrevistados eram as fichas formativas e sumativas, os relatórios científicos e os registos de observação, como se exemplifica nas seguintes citações: "Atualmente os meus alunos realizam os seus testes sumativos em ambiente digital, recorrendo a computadores portáteis. Utilizo o software quizfaber para criar os testes" (Professor 1); "Avaliação formativa através de relatórios cientificos que permitem avaliar a observação dirigida, a análise de resultados, o à-vontade com técnicas de laboratório, a capacidade de sintese, a comunicação, os conhecimentos básicos num conteúdo e o raciocinio" (Professor 4).

O acréscimo da utilização das TIC em contexto de sala de aula, anteriormente já referido nos resultados do questionário, é corroborado pelo discurso do Professor 1 quando se refere ao modo como concretiza a avaliação das aprendizagens dos alunos.

Os entrevistados salientaram a mobilização de conhecimentos e a promoção de autonomia e de espírito crítico como principais benefícios inerentes à actual abordagem curricular por competências, mencionando que: "O desenvolvimento de competências contribui para aumentar a autonomia nos alunos face a novas situações" (Professor 4) e que "Os alunos são preparados para algo mais global e transversal, para interpretarem criticamente as situações reais do dia-a-dia. Atualmente, os meus alunos conseguem ir «buscar» informações relevantes a outras disciplinas e relacioná-las" (Professor 5). Alguns autores, por exemplo Zabala e Arnau (2007), sustentam que a mobilização de conhecimentos em situações distintas e a intervenção eficaz face aos contextos são aportes fundamentais à formação integral dos indivíduos e à construção da personalidade.

Os constrangimentos inerentes à atual abordagem curricular por competências, assinalados pelos professores entrevistados, foram de natureza extrínseca aos próprios, situandose em três níveis:

i) Envolvimento dos alunos - "Alguns alunos recusam-se a ler os artigos, outros não conseguem interpretar, muitos não querem redigir resposta, então têm de ser subtilmente levados a querer" (Professor 4); 
Martins, I. et al.

ii) Organização e recursos - "Limitaçoes organizacionais e financeiras impedem que se realizem aulas de campo; o não desdobramento das turmas do $9^{\circ}$ Ano inviabiliza a realização de verdadeiras aulas laboratoriais" (Professor 1);

iii) Gestão de tempo - "A abordagem curricular por competências raramente se consegue concretizar devido às dificuldades decorrentes da gestão do tempo para dar todos os conteúdos programáticos" (Professor 3).

Importa destacar que a excessiva preocupação com o cumprimento do programa tende a refletir-se na adoção de métodos de ensino predominantemente transmissivos (HARGREAVES; EARL, 1990), podendo acarretar efeitos nefastos para a qualidade do ensino (FULLAN; HARGREAVES, 2001), entre eles, a priorização da memorização de conceitos em detrimento da compreensão dos processos. A este propósito, Roldão (2003) esclarece que o programa não é um normativo a cumprir, é um plano de ação, um instrumento (entre outros), de operacionalização do currículo.

As implicações inerentes à implementação do processo de Reorganização Curricular foram, segundo o discurso dos entrevistados, mais evidentes ao nível da organização curricular: "A redução do número de alunos por turma ajudou bastante. Uma vez que as turmas estão em desdobramento e leciono a meia turma, posso realizar mais atividades experimentais" (Professor 4). Esta sobrevalorização das implicações de natureza organizacional é consentânea com o facto da generalidade dos entrevistados e de cerca de metade dos professores respondentes ao questionário ter afirmado que a implementação do processo de Reorganização Curricular não os induziu a introduzir alterações significativas nas suas práticas curriculares.

\section{d) Dinâmicas de trabalho docente}

A análise dos resultados do questionário permite-nos constatar que a implementação do processo de Reorganização Curricular do Ensino Básico induziu 49,6\% dos professores respondentes a alterar as formas de trabalhar com os seus pares. Segundo os professores respondentes, as situações de trabalho entre pares cuja frequência sofreu maior acréscimo foram as que se encontram ilustradas na Tabela 3.

Uma leitura mais atenta das situações de trabalho entre pares cuja frequência de utilização aumentou permite detectar que as que obtiveram maiores valores percentuais estão

Tabela 3. Situações de trabalho entre pares cuja frequência aumentou.

\begin{tabular}{lc}
\hline \multicolumn{1}{c}{ Situações de trabalho entre pares cuja frequência aumentou } & Percentagem \\
\hline Construção, revisão, aplicação e avaliação conjunta do Projeto Curricular de Turma. & $68,0 \%$ \\
Análise conjunta da situação da turma e identificação das características específicas dos & $63,7 \%$ \\
alunos. & $62,3 \%$ \\
Análise e discussão conjunta dos critérios de avaliação dos alunos. & $60,3 \%$ \\
Gestão flexível do currículo, adotando conjuntamente estratégias de ensino diferenciadas e & $41,3 \%$ \\
adequadas aos diferentes alunos, potenciando as suas aprendizagens. & $39,4 \%$ \\
Formação e debate com os colegas, visando a melhoria da qualidade das práticas pedagógicas. & $37,0 \%$ \\
ldentificação conjunta das necessidades de formação dos professores do Departamento & $36,5 \%$ \\
Construção partilhada de material didático-pedagógico. & \\
Planificação conjunta de atividades experimentais. &
\end{tabular}

Fonte: Os autores. 
associadas ao PCT, presumivelmente pelo carácter obrigatório atribuído à construção deste instrumento de gestão curricular no período pós implementação do processo de Reorganização Curricular do Ensino Básico.

$\mathrm{Na}$ tentativa de compreender o aumento destas situações específicas de trabalho entre pares, questionámos os seis professores entrevistados sobre a finalidade que atribuíam ao PCT e em que medida contribuíam para a sua construção. A análise do discurso dos entrevistados revelou que a responsabilidade pela construção deste instrumento de gestão curricular era atribuída quase exclusivamente ao diretor de turma. Esta aparente falta de envolvimento docente indicia que os professores sentem dificuldades em compreender e trabalhar segundo uma lógica de projetos curriculares. Face a esta realidade, e não obstante o carácter mobilizador da ação subjacente ao conceito de "Projeto", os dados induzem-nos a questionar se o PCT não estará a transformar-se em mais um instrumento burocratizado das práticas curriculares (ROLDÃO, 2004b).

Os resultados obtidos demonstram que a implementação do processo de Reorganização Curricular compeliu 41,3\% dos professores respondentes a procurar formação e a incrementar situações de debate com os colegas, numa perspectiva de melhorar as práticas pedagógicas. A obtenção de formação poderá traduzir-se em melhores níveis de desempenho profissional, estando este, segundo a comunicação da European Commission (2007), relacionado com o sucesso das aprendizagens dos alunos.

Importa destacar que, a frequência de situações de trabalho colaborativo entre professores, particularmente a planificação e a construção conjunta de materiais didáticos, não aumentou substancialmente, comparativamente ao acréscimo verificado com as situações relativas à construção do PCT. Esta realidade aproxima-se dos resultados de estudos desenvolvidos por Hargreaves (1998); Lima (2002; 2004) e McLaughlin e Talbert (2001), os quais demonstram que situações de partilha e construção conjunta de materiais didático-pedagógico entre docentes não ocorrem com a frequência desejável. Contudo, consideramos que estas situações de colaboração docente se assumem como condições fundamentais para a concretização dos PCT.

Com a aplicação do inquérito por questionário pretendíamos, ainda, averiguar a forma de trabalho privilegiada pelos professores que lecionavam as disciplinas da área de CFN, encontrando-se os resultados obtidos organizados na Tabela 4.

Tabela 4. Formas de trabalho docente privilegiadas pelos professores respondentes.

\begin{tabular}{|c|c|c|c|c|}
\hline Formas de trabalho docente privilegiadas & Nunca & $\begin{array}{l}\text { Poucas } \\
\text { vezes }\end{array}$ & $\begin{array}{l}\text { Algumas } \\
\text { vezes }\end{array}$ & $\begin{array}{l}\text { Muitas } \\
\text { vezes }\end{array}$ \\
\hline & \multicolumn{4}{|c|}{$\%$} \\
\hline Trabalho individual. & 0,0 & 2,9 & 16,2 & 80,9 \\
\hline Trabalho com colegas com quem sente maior proximidade afetiva. & 2,7 & 25,9 & 52,2 & 19,2 \\
\hline $\begin{array}{l}\text { Trabalho com colegas do seu departamento curricular que lecionam, } \\
\text { simultaneamente, a mesma disciplina e ano de escolaridade. }\end{array}$ & 1,9 & 11,7 & 57,2 & 29,2 \\
\hline Trabalho com colegas de outros departamentos curriculares. & 9,1 & 62,2 & 26,7 & 2,0 \\
\hline Trabalho com colegas de outras escolas. & 40,6 & 46,3 & 12,3 & 0,9 \\
\hline
\end{tabular}

Fonte: Os autores. 
Martins, I. et al.

Os dados da tabela permitem-nos constatar que o trabalho individual continuava a ser a forma de trabalhar privilegiada pela generalidade (80,9\%) dos professores de CFN respondentes. Esta realidade corrobora resultados de diferentes investigações realizadas sobre a temática dinâmicas de trabalho docente, nomeadamente Perrenoud (1999); Tardif e Lessard (2005); Williams, Prestage e Bedward (2001). Saliente-se que, autores como Fullan e Hargreaves (2001) entendem a prevalência do individualismo docente como uma consequência da própria organização escolar (arquitetura, organização de tempos e espaços), por sua vez Carpentier-Roy e Pharand (1992) e Lima (2002) associam esta situação a questões de personalidade.

Estes dados do questionário foram corroborados pelo discurso da generalidade dos professores entrevistados quando afirmaram que o trabalho individual era a sua forma de trabalhar privilegiada. Segundo os entrevistados, o trabalho individual era uma condição imprescindível à posterior ocorrência de situações de trabalho colaborativo docente, como se exemplifica na afirmação: "Antes de haver trabalho colaborativo, tem de haver por parte de cada um dos professores um trabalho de carácter individual, este tem de se inteirar dos assuntos, pesquisar, refletir, o que depois se torna muito mais vantajoso para a discussão e partilha de ideias em grupo" (Professor 5).

Saliente-se que nas situações em que os professores respondentes ao questionário optavam por trabalhar entre pares privilegiavam os colegas que lecionavam a mesma disciplina e ano de escolaridade (86,4\%) e/ou os que lhes eram afetivamente mais próximos $(71,4 \%)$. Aspectos, uma vez mais, confirmados através do discurso dos entrevistados quando se referiram ao departamento curricular como a estrutura de gestão intermédia com maior índice de colaboração docente, destacando os subgrupos de trabalho organizados por disciplina e ano de escolaridade. Com efeito, a importância atribuída a estes subgrupos de trabalho era notória, nomeadamente em situações de esclarecimento de dúvidas: "Recorro aos meus pares que lecionam a mesma disciplina" (Professor 2).

Os professores de CFN envolvidos neste estudo ao focalizarem-se nos aspectos relativos à disciplina que lecionavam reproduziam o que Hargreaves (1998) denomina de situações de "balcanização" no seio do próprio departamento. Ressalve-se, no entanto, que uma cultura de colaboração docente não se contrapõe à presença de subgrupos de trabalho, porém pressupõe a existência de fronteiras mais ténues e com identidades menos estanques.

Por sua vez, o trabalho docente com colegas pertencentes a outros departamentos era uma realidade pouco comum entre os professores de CFN respondentes ao questionário, tendo destes 71,3\% afirmado "Nunca" ou "Poucas Vezes" o realizar. Esta situação indicia o predomínio de uma cultura docente balcanizada, facto que constrange a partilha de práticas curriculares e, por conseguinte, o desenvolvimento profissional. Nesta sequência, os processos de ensino e aprendizagem dos alunos são, igualmente, condicionados, dado que, segundo Goodson (1997), este tipo de cultura docente não potencia a articulação de saberes entre as diferentes áreas.

Os resultados do questionário permitem, ainda, verificar que as relações de trabalho estabelecidas entre professores de diferentes escolas eram escassas (13,2\%), contudo, segundo Eaker, DuFour e DuFour (2002); Goodson (2008); Little (2003) e Martin-Kniep (2004), o conhecimento e a análise de realidades escolares diferentes tende a promover o desenvolvimento profissional docente, através do intercâmbio e da partilha de conhecimentos e experiências. Os professores entrevistados, referindo-se aos benefícios que atribuíam à colaboração docente, agruparam-nos em dois níveis: 
i) Desenvolvimento profissional - "Aumenta o conbecimento em áreas que não dominamos ou que temos dúvidas" (Professor 3); "Ao discutirmos assuntos com outras pessoas e ao partilharmos material estamos sempre a aprender" (Professor 6);

ii) Melhoria do trabalho docente - "Rentabiliza-se o trabalho com a partilha de recursos de ensino e aprendizagem" (Professor 2); "Melhora a qualidade do trabalho desenvolvido [...] permite a evolução franca das metodologias, materiais e o desenvolvimento de projetos" (Professor 4).

Por outro lado, os principais constrangimentos apontados pelos entrevistados ao desenvolvimento de colaboração docente relacionavam-se com:

i) Gestão do tempo - "Não há tempo em comum para se poder trabalhar [...] falta de tempo e de conciliação de horários dos professores" (Professor 5);

ii) Receio de exposição - "O medo e a vergonha de admitirem que têm dúvidas" (Professor 3);

iii) Cultura de individualismo - "Não pensamos na escola como um projeto, pensamos mais na nossa área especifica e que o importante é fazer tudo direitinho na minha sala de aula e, assim, ninguém me aborrece" (Professor 5).

Importa salientar que a falta de tempo e as dificuldades de conciliação de horários de trabalho foram constrangimentos mencionados pela totalidade dos professores de CFN entrevistados, como condicionantes ao desenvolvimento de colaboração docente. O discurso sobre o receio de exposição vai ao encontro de resultados de estudos desenvolvidos por Friend e Bauwens (1988) e Tardif e Lessard (2005), segundo os quais o motivo subjacente ao receio de expor dúvidas reside na possibilidade de os pares os considerarem menos competentes.

As condições ideais que, segundo os entrevistados, facilitariam a ocorrência de maiores índices de colaboração docente situavam-se ao nível da: i) diminuição do excesso de burocracia, ii) marcação de tempos comuns de trabalho nos horários dos professores, iii) maior disponibilidade e predisposição dos docentes e iv) existência de equipas de liderança que fomentem o desenvolvimento de trabalho colaborativo.

A opinião dos entrevistados era discordante em relação ao impacto da implementação do processo de Reorganização Curricular do Ensino Básico nas dinâmicas de trabalho docente. Os quatro entrevistados que afirmaram que a implementação deste processo os compeliu a alterarem as suas dinâmicas de trabalho docente salientaram um acréscimo de trabalho colaborativo: "Alterei a minha forma de trabalhar com os colegas, pois senti maior necessidade de trabalhar colaborativamente" (Professor 5).

Em contrapartida, os restantes dois entrevistados justificaram a não alteração das suas dinâmicas de trabalho reportando-se a argumentos de natureza organizacional, como evidenciam as afirmações:

"No concreto a Reorganização Curricular veio apenas distribuir a carga horária de uma forma diferente. A escola não mudou, por terem mudado os documentos oficiais. [...] Veio aumentar o número de turmas e alunos de cada professor, reduzindo a disponibilidade individual" (Professor 1)

"Passámos a reunir mais vezes, o que não quer dizer que tenbamos passado a trabalhar mais colaborativamente. Houve sim necessidade de analisar e discutir os novos documentos do Ministério da Educação" (Professor 6). 
Martins, I. et al.

Os argumentos apresentados pelos entrevistados que afirmaram não ter alterado as suas dinâmicas de trabalho na sequência da implementação do Processo de Reorganização Curricular são de natureza extrínseca aos próprios, indiciando alguma falta de envolvimento em relação aos pressupostos inerentes à implementação deste processo.

\section{Considerações finais}

Os resultados deste estudo demonstram que a implementação do processo de Reorganização Curricular do Ensino Básico, e consequente perspectiva curricular por competências, apenas induziu cerca de $50,0 \%$ dos professores respondentes a alterarem as suas práticas curriculares e dinâmicas de trabalho com os pares. Saliente-se que, segundo o discurso dos professores entrevistados, a implementação deste processo não se traduziu em mudanças significativas, quer no contexto das práticas curriculares como no das dinâmicas de trabalho docente.

As principais alterações apontadas ao nível das práticas curriculares referem-se a um acréscimo da utilização das TIC, da promoção de debates sobre problemáticas CTS e da integração de saberes transversais. O aumento destas situações curriculares aproxima-se do preconizado pelas linhas de ação do atual discurso educativo da área das CFN, em particular no que respeita: i) ao desenvolvimento articulado das competências específicas desta área, ii) à promoção de experiências educativas diversificadas e contextualizadas segundo uma perspectiva CTS e iii) ao acréscimo dos índices de literacia científica (GALVÃO; FREIRE, 2004).

Os principais constrangimentos à realização de práticas curriculares perspectivadas para o desenvolvimento de competências nos alunos foram: i) a falta de envolvimento dos alunos, ii) a preocupação com o cumprimento do programa e iii) problemas organizacionais e de gestão de tempo. Importa destacar que a natureza destes constrangimentos é extrínseca aos professores de CFN respondentes. Por outro lado, não obstante os professores terem revelado uma certa familiarização com alguns dos conceitos-chave do atual discurso educativo, são escassos os indícios da sua (re)apropriação ao nível da prática e do trabalho docente (ROLDÃO, 2004a). Esta apropriação superficial, segundo Roldão (2004a), traduz um conjunto de fatores associados à cultura profissional e ao insuficiente domínio de conhecimento teórico sobre os conceitos, refletindo o que Goodson (2008) caracteriza por funcionamento da escola como organização onde tendem a persistir lógicas e rotinas cristalizadas.

As alterações salientadas no contexto das dinâmicas de trabalho docente relacionavam-se com aspectos organizacionais, tais como a realização de um maior número de reuniões de trabalho e o aumento de documentos a preencher. A partilha de saberes e a construção de materiais didáticos entre docentes era escassa, prevalecendo uma cultura de individualismo, a qual carece de uma melhor compreensão dos fatores que lhe estão subjacentes. Com efeito, o diagnóstico que atribui a responsabilidade da sua permanência exclusivamente aos professores é, segundo Flinders (1988); Fullan e Hargreaves (2001) e Little (1990), demasiado simplista. Importa destacar que, para Fullan e Hargreaves (2001) e Rosenholtz (1985), a organização escolar (arquitetura, espaços e tempos livres) é, igualmente, apontada como argumento que restringe o desenvolvimento de práticas de colaboração docente.

Em suma, a generalidade dos resultados corrobora o facto das mudanças curriculares constituírem um processo complexo, moroso e difícil para os professores, conduzindo a mai- 
ores índices de inquietação e carecendo de muita disponibilidade de tempo (GUSKEY, 2002). Por outro lado, permitem deduzir que a relação que a maioria dos professores envolvidos no estudo estabelece com as práticas curriculares e as dinâmicas de trabalho docente é diferente da preconizada nos discursos da tutela e da investigação educacional (LOPES, 2008). A responsabilidade deste desfasamento entre o discurso político e educacional e a realidade das práticas e dinâmicas de trabalho docente não pode ser atribuída exclusivamente aos professores, dado que a administração central não tem promovido políticas consistentes ao nível da formação inicial e contínua dos professores. Neste sentido, Costa (2007, p. 107) invoca a necessidade de "mecanismos de acompanhamento, monitorização e avaliação do processo de implementação da reorganização curricular".

Deste modo, torna-se urgente aprofundar a compreensão do referido desfasamento e apontar mecanismos passíveis de o minimizar, os quais poderão, entre outros, traduzir-se na: (i) definição e concepção de políticas curriculares que tenham em consideração as realidades do nível meso (escola) e micro (sala de aula); (ii) implementação e concretização de um maior número de projetos em parceria os quais, envolvendo professores e investigadores, perspectivem soluções para problemas diagnosticados no contexto das práticas e produzam conhecimento sustentado sobre estas (iii) reestruturação dos cursos de formação inicial e contínua de professores, organizando-os segundo uma perspectiva colaborativa e promotora do desenvolvimento de competências de natureza colaborativa; (iv) realização de ações de formação coconcebidas e codesenvolvidas segundo as necessidades e problemas diagnosticados pelos professores e investigadores, especialmente no campo da abordagem curricular por competências; (v) reorganização das dinâmicas internas das escolas, nomeadamente ao nível das equipas de liderança e da criação de condições facilitadoras do desenvolvimento de trabalho colaborativo docente e (vi) partilha e divulgação das experiências educativas de sucesso junto das comunidades educativa e científica, nomeadamente através da publicação de artigos científicos realizados em coautoria por elementos de ambas as comunidades.

Nesta perspectiva, Guskey (2002) apela à necessidade de uma maior implicação dos professores nas reformas educativas e na melhoria da qualidade do ensino, dado ser fundamental alcançar maiores índices de envolvimento, de responsabilização e de colaboração docente, assegurando, no entanto, a individualidade e as idiossincrasias de cada professor. Em última instância, emerge a necessidade de um esforço concertado e, sobretudo, uma convergência de perspectivas de análise e de ação entre a administração central, as instituições de formação de professores, a comunidade científica e as escolas.

\section{Agradecimentos}

Este artigo insere-se no contexto de dois projetos de doutoramento realizados no Laboratório de Avaliação da Qualidade Educativa (LAQE), estrutura funcional do Centro de Investigação Didáctica e Tecnologia na Formação de Formadores (CIDTFF) da Universidade de Aveiro. Os referidos projetos de doutoramento foram financiados pela Fundação para a Ciência e Tecnologia (SFRH/BD/28080/2006 e SFRH/BD/36192/2007). 
Martins, I. et al.

\section{Referências}

BEANE, J. Integração curricular: a essência de uma escola democrática. In: PACHECO, J. A.; MORGADO, J.; VIANA, I. (Org.). Políticas curriculares: caminhos da flexibilização e integração. Braga: Universidade do Minho, 2000. p. 45-61.

CACHAPUZ, A.; PRAIA, J.; JORGE, M. Ciência, educação em ciência e ensino das ciências. Lisboa: Ministério da Educação; Instituto da Inovação Educacional, 2002.

CARPENTIER-ROY, M.; PHARAND, S. Organisation du travail et santé mentale chez les enseignantes et les enseignantes du primaire et du secondaire. Quebec: Communications CEQ, 1992.

COSTA, N. Um olhar sobre o ensino das Ciências na escolaridade básica - o lugar da investigação em didáctica na promoção da sua qualidade. In: SANTOS, M. (Org.). Ciência e educação em ciência. Lisboa: Conselho Nacional de Educação; Ministério da Educação, 2007. p. 95-115.

DEBOER, G. Scientific literacy: another look at its historical and contemporary meanings and its relationship to science education reform. Journal of Research in Science Teaching, Maryland, v. 37, n. 6, p. 582-601, 2000.

EAKER, R.; DUFOUR, R.; DUFOUR, R. Getting started: reculturing schools to become professional learning communities. Bloomington: National Education Service, 2002.

EUROPEAN COMMISSION. Science education now: a renewed pedagogy for the future of Europe. Brussels: European Commission, 2007. Disponível em: <http:// bookshop.europa.eu/en/science-education-now-pbKINA22845/>. Acesso em: 14 nov. 2009.

FLINDERS, D. Teacher isolation and the new reform. Journal of Curriculum and Supervision, Alexandria, v. 4, n. 1, p. 17-29, 1988.

FRIEND, M.; BAUWENS, J. Managing resistance: an essential consulting skill for learning disabilities teachers. Journal of Learning Disabilities, California, v. 21, n. 9, p. 556-561, 1988.

FULLAN, M.; HARGREAVES, A. Por que é que vale a pena lutar? O trabalho de equipa na escola. Porto: Porto Editora, 2001.

GALVÃO, C.; FREIRE, A. A perspectiva CTS no currículo das Ciências Físicas e Naturais em Portugal. In: MARTINS, I.; PAIXÃO, F.;. VIEIRA, R. (Org.). Perspectivas ciência-tecnologia-sociedade na inovação da educação em ciência. Aveiro: Universidade de Aveiro, 2004. p. 31-38.

GOODSON, I. Conhecimento e vida profissional. Porto: Porto Editora, 2008.

GOODSON, I. The changing curriculum: studies in social construction. New York: Peter Lang, 1997.

GUSKEY, T. Professional development and teacher change. Teachers and Teaching: theory and practice, Nottingham, v. 8, n. 3/4, p. 381-391, 2002. 
Impacto do currículo português ...

HARGREAVES, A. Os professores em tempos de mudança: o trabalho e a cultura dos professores na idade pós-moderna. Amadora: McGraw-Hill, 1998.

HARGREAVES, A.; EARL, L. Rights of passage. Toronto: Ontario Ministry of Education, 1990.

HORN, I. Learning on the job: a situation account of teacher learning in high school mathematics departments. Cognition and Instruction, Mahwah, v. 23, n. 2, p. 207-236, 2005.

LANG, V. A profissão de professor na França: permanência e fragmentação. In: TARDIF, M.; LESSARD, C. (Orgs.). O ofício de professor: história, perspectivas e desafios internacionais. Petrópolis: Vozes, 2008. p. 152-166.

LAUGKSCH, R. Scientific literacy: a conceptual overview. Science Education, Hoboken, v. 84, n. 1, p. 71-94, 2000.

LEE, M.; ERDOGAN, I. The effect of science-technology-society teaching on students: attitudes toward science and certain aspects of creativity. International Journal of Science Education, London, v. 29, n. 11, p. 1315-1327, 2007.

LEITE, C.; GOMES, L.; FERNANDES, P. Projectos curriculares de escola e de turma. Porto: Edições Asa, 2001.

LIMA, J. As culturas colaborativas nas escolas: estruturas, processos e conteúdos. Porto: Porto Editora, 2002.

LIMA, J. O currículo construído: da autonomia da escola à colaboração profissional entre os docentes. Revista de Estudos Curriculares, Braga, v. 2, n. 1, p. 57-84, 2004.

LITTLE, J. Constructions of teacher leadership in three periods of policy and reform activism - school teacher: a sociological study. Chicago: University of Chicago Press, 2003.

The persistence of privacy: autonomy and initiative in teachers' professional

relations. Teachers College Record, New York, v. 91, n. 4, p. 509-536, 1990.

LOPES, A. Políticas de integração curricular. Rio de Janeiro: Eduerj, 2008.

MARTIN-KNIEP, G. Developing learning communities through teacher expertise. Thousand Oaks: Corwin Press, 2004.

MCLAUGHLIN, M.; TALBERT, J. Professional communities at the work of high school teaching. Chicago: University of Chicago Press, 2001.

MCWILLIAM, E.; PORONNIK, P.; TAYLOR, P. Re-designing science pedagogy: reversing the flight from science. Journal of Science Education \& Technology, Dordrecht, v. 17, n. 3, p. 226-235, 2008.

MISKEL, C.; MCDONALD, D.; BLOOM, S. Structural and expectancy linkages within schools and organizational effectiveness. Educational Administration Quarterly, Salt Lake City, v. 19, n. 1, p. 49-82, 1983. 
Martins, I. et al.

NÓVOA, A. O passado e o presente dos professores. In: . (Org.). Profissão professor. Porto: Porto Editora, 1995. p. 13-34.

ORGANISATION FOR ECONOMIC CO-OPERATION AND DEVELOPMENT. PISA 2006: Science competencies for tomorrow's world. Paris: OECD, 2007.

OSBORNE, J.; DILLON, J. Science education in Europe: critical reflections. London: The Nuffield Foundation, 2008.

PERRENOUD, PH. L'établissement scolaire entre mandate projet: vers une autonomie relative. Genève: Faculté de Psychologie et des Sciences de l'Éducation, 1999.

PORTUGAL. Ministério da Educação. Departamento da Educação Básica. Currículo Nacional do Ensino Básico: competências essenciais. Lisboa: DEB, 2001a.

Ministério da Educação. Departamento da Educação Básica. Ciências físicas e naturais: orientações curriculares para o $3^{\circ}$ ciclo do Ensino Básico. Lisboa: DEB, 2001b.

ROLDÃO, M. C. Competências na cultura de escolas do $1^{\circ}$ Ciclo. In: CACHAPUZ, A.; SÁ-CHAVES, I.; PAIXÃO, F. (Orgs.). Saberes básicos de todos os cidadãos no séc. XXI. Lisboa: Conselho Nacional de Educação; Ministério da Educação, 2004a. p. 177-197.

Gestão do currículo e avaliação de competências: as questões dos professores. Lisboa: Editorial Presença, 2003.

Quem supervisiona o quê? Liderança e colaboração no trabalho curricular da escola. In: SOUSA, O.; RICARDO, M. (Orgs.). Uma escola com sentido: o currículo em análise e debate - contextos, questões e perspectivas. Lisboa: Edições Universitárias Lusófonas, 2004b. p. 135-144.

ROSENHOLTZ, S. Effective schools: interpreting the evidence. American Journal of Education, Chicago, v. 93, n. 3, p. 352-388, 1985.

SAWYER, L.; RIMM-KAUFMAN, S. Teacher collaboration in the context of the responsive classroom approach. Teachers and Teaching: theory and practice, Oxfordshire, v. 13, n. 3, p. 211-245, 2007.

TARDIF, M.; LESSARD, C. O trabalho docente: elementos para uma teoria da docência como profissão de interacções humanas. Petrópolis: Vozes, 2005.

WILLIAMS, A.; PRESTAGE, S.; BEDWARD, J. Individualism to collaboration: the significance of teacher culture to the induction of newly qualified teachers. Journal of Education for Teaching, Manchester, v. 2 27, n. 3, p. 253-267, 2001.

YALVAC, B. et al. Turkish pre-service science teachers' views on science-technology-society issues. International Journal of Science Education, London, v. 29, n. 3, p. 331-348, 2007.

ZABALA, A.; ARNAU, L. 11 ideas clave: cómo aprender y enseñar competencias. Barcelona: Editorial Graó, 2007.

Artigo recebido em 16/06/2010. Aceito em 09/02/2011. 